LAWRENCE LIVERMORE N A T IO N A L LABORATORY
Experimental study of 351-nm and 527-nm laser-initiated surface damage on fused silica surfaces due to typical contaminants.

J. Honig, M. A. Norton, W. G. Hollingsworth, E. E. Donohue, M. A. Johnson

November 11, 2004

Boulder Damage Symposium XXXVI Boulder, CO, United States September 19, 2004 through September 22, 2004 
This document was prepared as an account of work sponsored by an agency of the United States Government. Neither the United States Government nor the University of California nor any of their employees, makes any warranty, express or implied, or assumes any legal liability or responsibility for the accuracy, completeness, or usefulness of any information, apparatus, product, or process disclosed, or represents that its use would not infringe privately owned rights. Reference herein to any specific commercial product, process, or service by trade name, trademark, manufacturer, or otherwise, does not necessarily constitute or imply its endorsement, recommendation, or favoring by the United States Government or the University of California. The views and opinions of authors expressed herein do not necessarily state or reflect those of the United States Government or the University of California, and shall not be used for advertising or product endorsement purposes. 


\title{
Experimental study of 351-nm and 527-nm laser-initiated surface damage on fused silica surfaces due to typical contaminants
}

\author{
John Honig, Mary A. Norton, William G. Hollingsworth, Eugene E. Donohue, Michael A. Johnson \\ Lawrence Livermore National Laboratories, L-462, P.O. Box 808, Livermore, CA 94551-0808
}

\begin{abstract}
Optics damage under high-intensity illumination may be the direct result of laser light interaction with a contaminant on the surface. Contaminants of interest are small particles of the materials of construction of large laser systems and include aluminum, various absorbing glasses, and fused silica. In addition, once a damage site occurs and begins to grow, the ejecta from the growing damage site create contamination on nearby optic surfaces and may initiate damage on these surfaces via a process we call "fratricide."

We report on a number of experiments that we have performed on fused silica optics that were deliberately contaminated with materials of interest. The experiments were done using $527-\mathrm{nm}$ light as well as $351-\mathrm{nm}$ light. We have found that many of the contaminant particles are removed by the interaction with the laser and the likelihood of removal and/or damage is a function of both fluence and contaminant size. We have developed an empirical model for damage initiation in the presence of contaminants.
\end{abstract}

Keywords: Laser damage, damage initiation, contamination

\section{INTRODUCTION}

Contamination plays a pivotal role in the ultimate performance in a number of optical systems. In the semiconductor industry, sub-micron sized contaminants can compromise a lithography step. Similar-sized contaminants introduced during optical coating runs are responsible for nodule-related damage events on high-reflectivity mirrors ${ }^{1}$. Larger-sized contaminants $(>1 \mu \mathrm{m})$ scatter laser light out of a propagating beam. In the presence of high-fluence, high-irradiance laser light, these same contaminants may couple with the laser light to create surface damage to the optic ${ }^{2,3,4}$. This laser-induced optic damage in the presence of contamination is sometimes due to diffraction effects and sometimes due to thermal effects. Models that describe these contamination-related damage processes have been developed. These models work quite well for well-defined contaminants and geometries. In general, contamination is not particularly well-defined, neither in size, geometry, nor constituency.

In the construction of large-scale lasers, materials are chosen carefully to minimize any deleterious effects. In spite of these efforts, contamination of optical surfaces can occur. The contaminants in these cases are the fused silica ejecta. Typical construction materials for lasers include aluminum, stainless steel and a host of absorbing glasses that are used to protect metal surfaces from high-irradiance laser light, such as SuperGrey ${ }^{5}, \mathrm{NG}^{6}$, and NG9. Besides the potential for contamination from construction material sources, contamination can also occur during laser operation. For example, a growing damage site on a fused silica surface can eject material onto itself as well as other optics downstream. While laser models typically include the effects of optical surface figure, optical wavefront, and thermal gradients on laser performance data, they rarely incorporate the effects of contamination. The goal of this work is to put contamination and its effects into a mathematical framework such that it can be incorporated into a laser system model. The effects of contaminant constituency, contaminant size, contaminated surface (input or exit surface), laser fluence, and laser wavelength $(351 \mathrm{~nm}$ and $527 \mathrm{~nm}$ ) are all examined.

\section{EXPERIMENT}

A primary goal of this experiment is to see the effects of high-fluence, high-irradiance laser light on realistic contaminants on fused silica surfaces. Contaminants are often created via typical manufacturing and building processes. Two such processes are abrasion and filing. Metal contaminants for this experiment were generated using a filing process shown 
in Fig.1. The particles were then sifted and sorted into various size bins and stored prior to deposition. Absorbing glass particles were generated using a mortar and pestle. The particles were also sifted and sorted into various size bins and stored prior to deposition. Four size bins were used: particles $<20 \mu \mathrm{m}$, particles between $20 \mu \mathrm{m}$ and $40 \mu \mathrm{m}$, particles between $40 \mu \mathrm{m}$ and $75 \mu \mathrm{m}$, and particles greater than $75 \mu \mathrm{m}$ (with no particles greater than $150 \mu \mathrm{m}$ ). Immediately prior to a particular experiment, particles of a single constituency from a single size bin were sprinkled onto one surface of a fused silica blank. All of the experiments described in this paper were performed on 5-cm diameter, SESO-polished, 7940 fused silica blanks. A cartoon of the experimental setup is shown in Fig. 2. Experiments were performed with contaminants on the front surface or with contaminants on the exit surface.

\section{Generate}

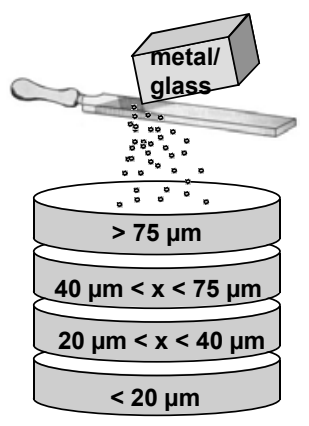

\section{Select}

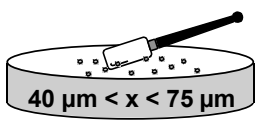

\section{Deposit}

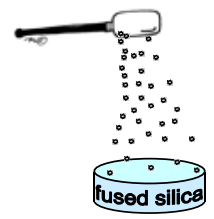

Figure 1. A cartoon describing how the contaminant particles for this experiment were generated, sorted, and deposited.
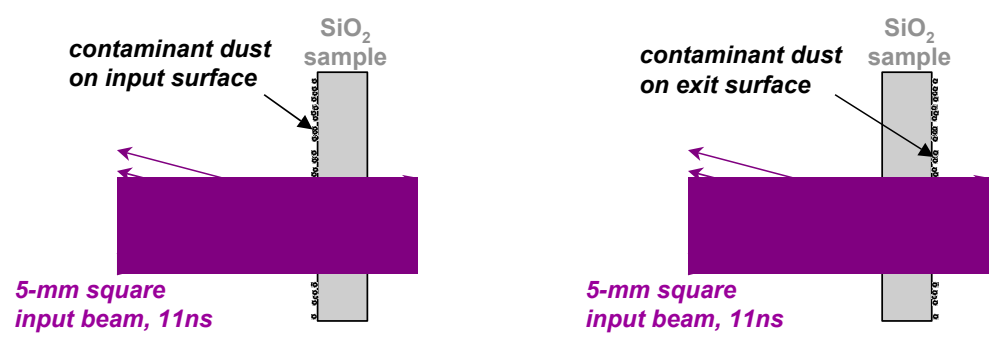

Figure 2. A cartoon showing the experimental setup for investigating the effect of contamination on input- and exitsurfaces.

Fused silica particles were generated in a different manner. These particles were generated using a laser beam interaction with a pre-initiated damage site as shown in Fig. 3. The pre-initiated site, located on the exit surface of the sample, was shot between 5 and 10 times with a 5 -mm-square, 10 -ns laser beam. The ejecta from the growing damage site landed on the catcher, located $1 \mathrm{~cm}$ away. The laser fluence during these growth shots was between 14 and $18 \mathrm{~J} / \mathrm{cm}^{2}$. Both the sample and the catcher could be translated together such that the growing, pre-initiated site was no longer in the beam. The effect of fused silica contamination on an input surface was examined in this fashion. To measure the effects of fused silica contamination on an exit surface, the catcher was turned around after accumulating ejecta from the growing, preinitiated damage site.
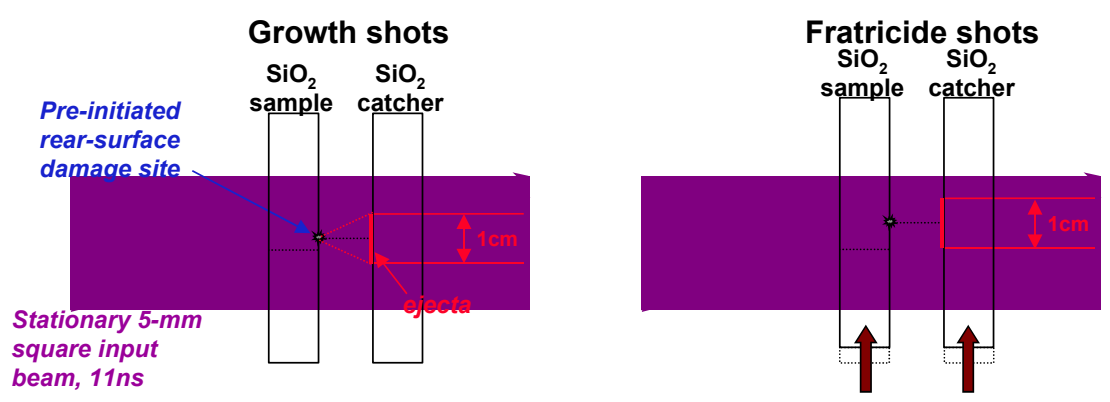

Figure 3. A cartoon showing how fused silica particles were generated from a growing, pre-existing damage site and deposited onto a sample.
The surfaces of the SESO-polished blanks were not modified in anyway to promote adherence of the particles. The contaminant particles stuck to the surfaces via entirely realistic and natural forces. Every attempt was made to create the most realistic contamination-related damage scenario possible.

The experiments were conducted in the Slab Lab facility at the Lawrence Livermore National Laboratory. The Slab 
Lab laser is a Nd:glass-based laser capable of generating near-diffraction-limited $20 \mathrm{~J}$ pulses at $1 \mathrm{~Hz}$ repetition rate ${ }^{7}$. Using highly deuterated KDP crystals, the 1053-nm fundamental beam can be frequency-converted to 527-nm or 351-nm operation. A photograph of the laser is shown in Fig. 4. The near-field profile of the Slab Lab laser is relatively consistent from shot to shot but does have significant peaks and valleys as shown in Fig. 5. However, the intensity profile variation over a 0.5 -mm square patch is $< \pm 20 \%$ shot to shot. When damage fluences are quoted later in this paper, they will correspond to the mean fluences in such a $0.5-\mathrm{mm}$ square patch.

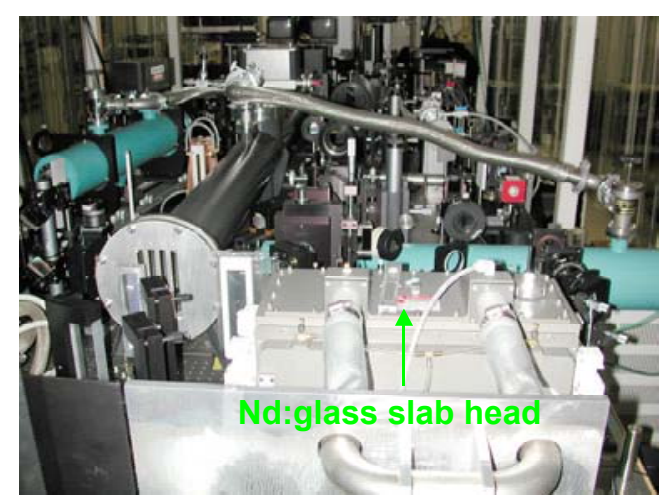

Figure 4. The 20J/pulse Nd:glass-based laser in the Slab Lab facility.
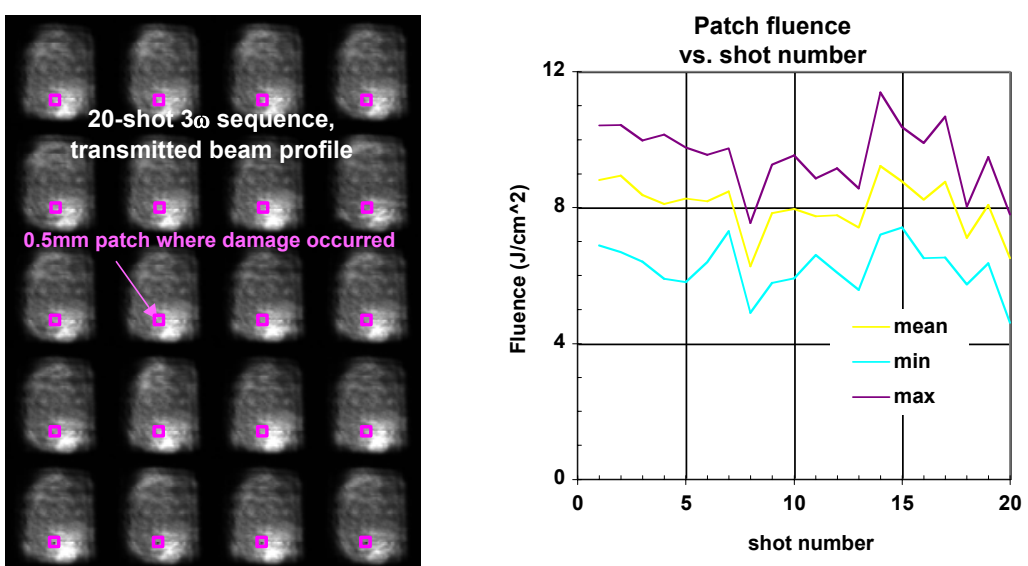

Figure 5. Near-field images of the 6x6mm Slab Lab laser and fluence statistics over a $0.5 \times 0.5 \mathrm{~mm}$ patch.

The experimental chamber is shown in Fig. 6. The contaminated sample of interest is loaded into the chamber and the chamber is evacuated to a pressure of 10 Torr. The Slab Lab laser light is beam formatted to hit the contaminated sample at a known fluence. The beam enters the chamber from the rear, interacts with the contaminated sample of interest, re-expands and strikes a beam dump $\sim 1 \mathrm{~m}$ away. There are two in-situ diagnostics that are used to monitor laser damage. The primary diagnostic is the transmitted beam image. A typical sequence of transmitted beam images showing a growing damage site are shown in Fig. 7. In this case, the damage is due to SuperGrey particles on the exit surface interacting with 10-ns, 527-nm light at $14.6 \mathrm{~J} / \mathrm{cm}^{2}$. In addition, a long-working length microscope connected to a video camera permits surface viewing. These data did not prove as fruitful for monitoring damage, primarily due to difficulties in lighting and small fields of view.

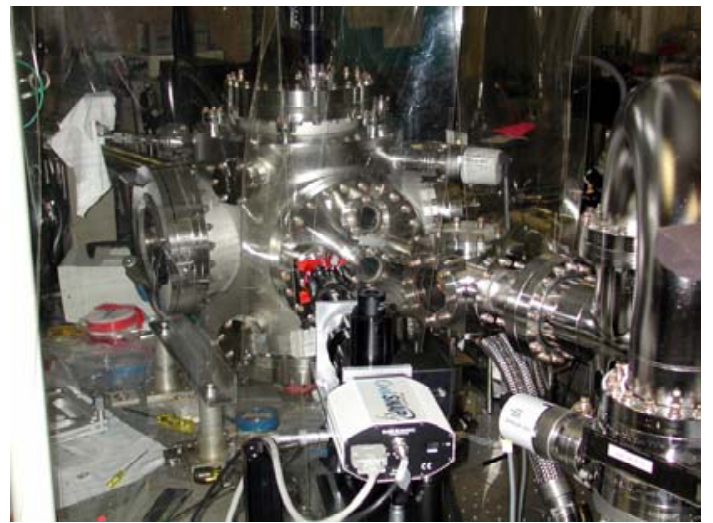

Figure 6. The 10-Torr experimental chamber that allows in situ viewing of damage events.

Post-experimental data collection consisted of both dark-field and bright-field microscopy (Fig. 8). From these data, one could determine particle sizes as well as damage morphology and location.

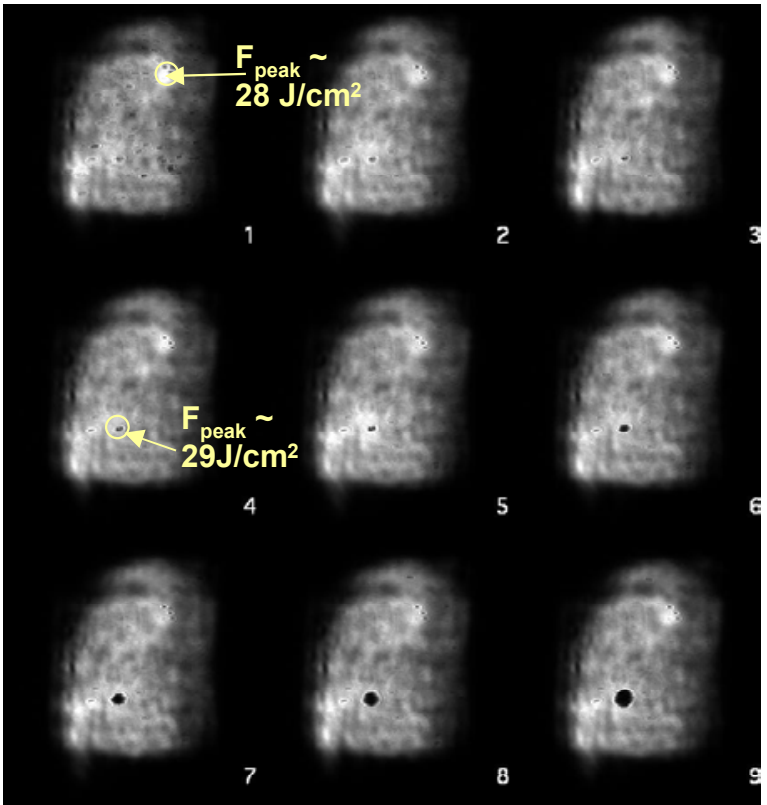

Figure 7. Near-field transmitted beam images showing a damage event and subsequent growth. 


\section{EXPERIMENTAL RESULTS}

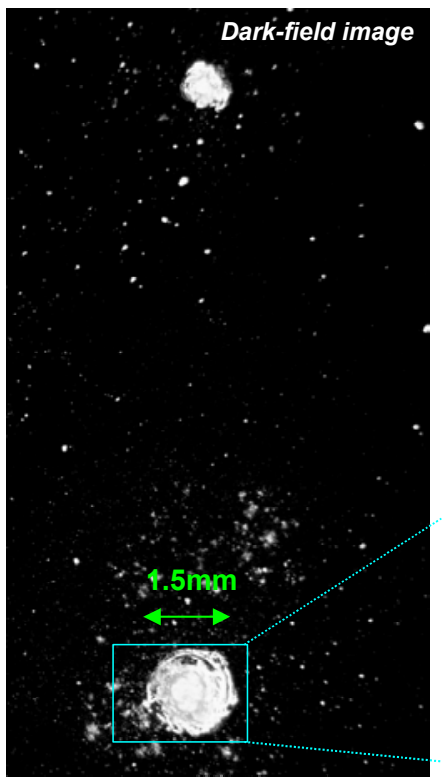

Figure 8. Damage sites and particles from this contamination experiment viewed with dark-field and brightfield microscopy.

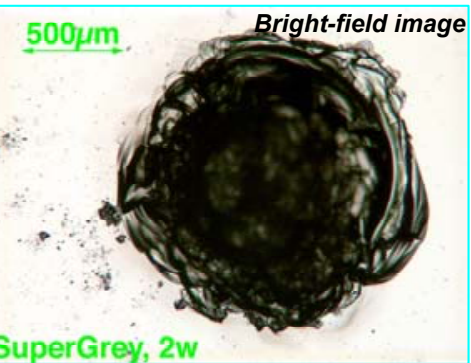

Data reduction involved analyzing images such as those shown in Figs. 7 and 8 . It was necessary to correlate the input beam images with the transmitted beam images to obtain accurate fluence measurements at damage, and non-damage locations. In some instances, no damage was seen as shown in Fig. 9. In many of these no-damage cases such as shown in Fig. 9, we observed a significant amount of surface cleaning due to the laser light. In other instances, input-surface contamination could result in both input-surface and exit-surface damage as shown in Fig. 10. In most cases when using 351-nm light, once damage occurred at a site, the damage would continue to grow in a manner described by Norton ${ }^{8,9}$. The resultant data using 527-nm light were somewhat more erratic.

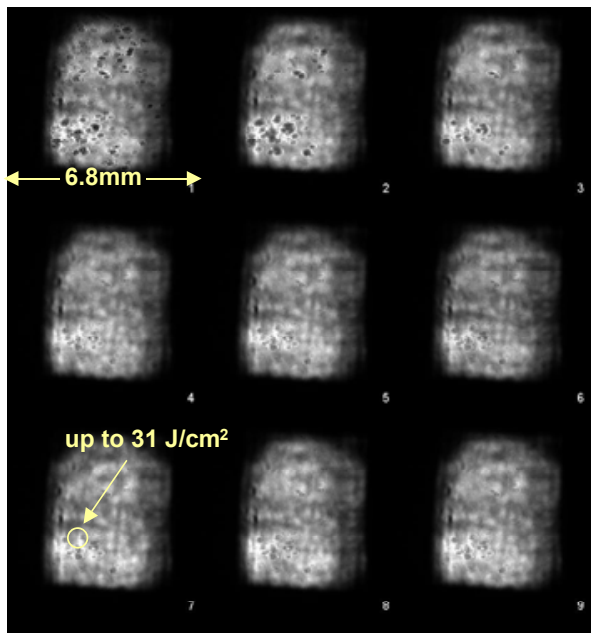

Figure 9. A 9-shot sequence of nearfield beam images showing some surface cleaning and no damage for $527-\mathrm{nm}$ fluences up to $31 \mathrm{~J} / \mathrm{cm}^{2}$.
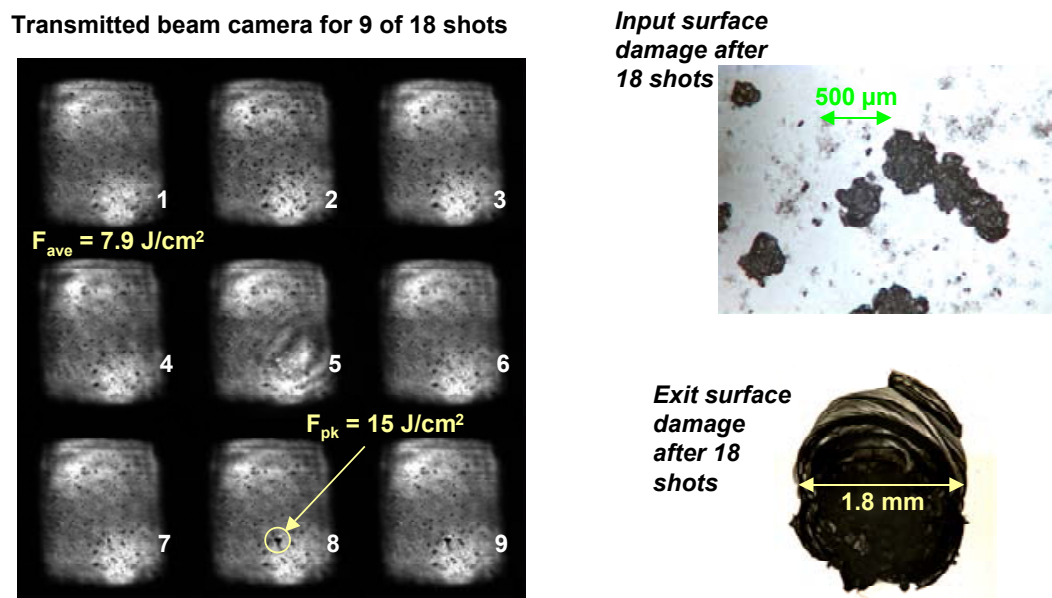

Figure 10. A 9-shot sequence of transmitted beam images and microscope images showing input- and exit-surface damage for $15 \mathrm{~J} / \mathrm{cm}^{2}, 351-\mathrm{nm}$ irradiation of input-surface SuperGrey particles.

When damage occurred due to metal contaminants, the damage was preceded by particle melting (Fig. 11).

A summary of the experimental results is shown in Fig. 12. The damage thresholds (in $\mathrm{J} / \mathrm{cm}^{2}$ ) as a function of contaminant species are shown for the following cases: exit-surface contamination/exit-surface damage, input-surface 


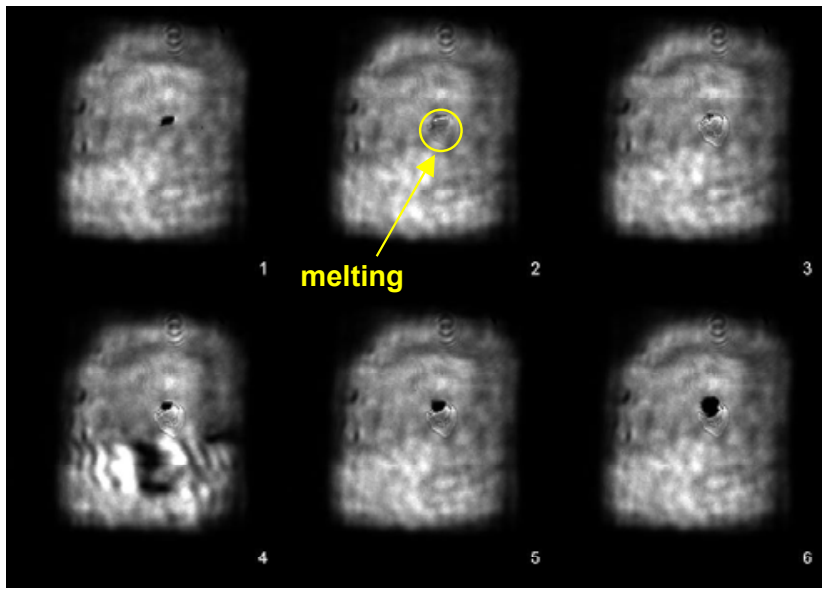

contamination/exit-surface damage, and input-surface contamination/input-surface damage. Data are presented for $2 \omega$ $(527-\mathrm{nm})$ and $3 \omega(351-\mathrm{nm})$ illumination. Where no data are presented, no data were taken. The single-hatched bars indicate that no damage was seen up to the highest levels achievable by the laser. No damage, due to fused silica particles, was seen using $527-\mathrm{nm}$ illumination at fluences up to $41 \mathrm{~J} / \mathrm{cm}^{2}$. The cross-hatched bars indicate that damage was observed but there was no subsequent growth. With the exception of fused silica, no damage was seen due to any particle smaller than $50 \mu \mathrm{m}$.

Figure 11. A 6-shot sequence of transmitted beam images showing the melting and subsequent damage due to an aluminum particle on the exitsurface interacting with 527-nm irradiation.

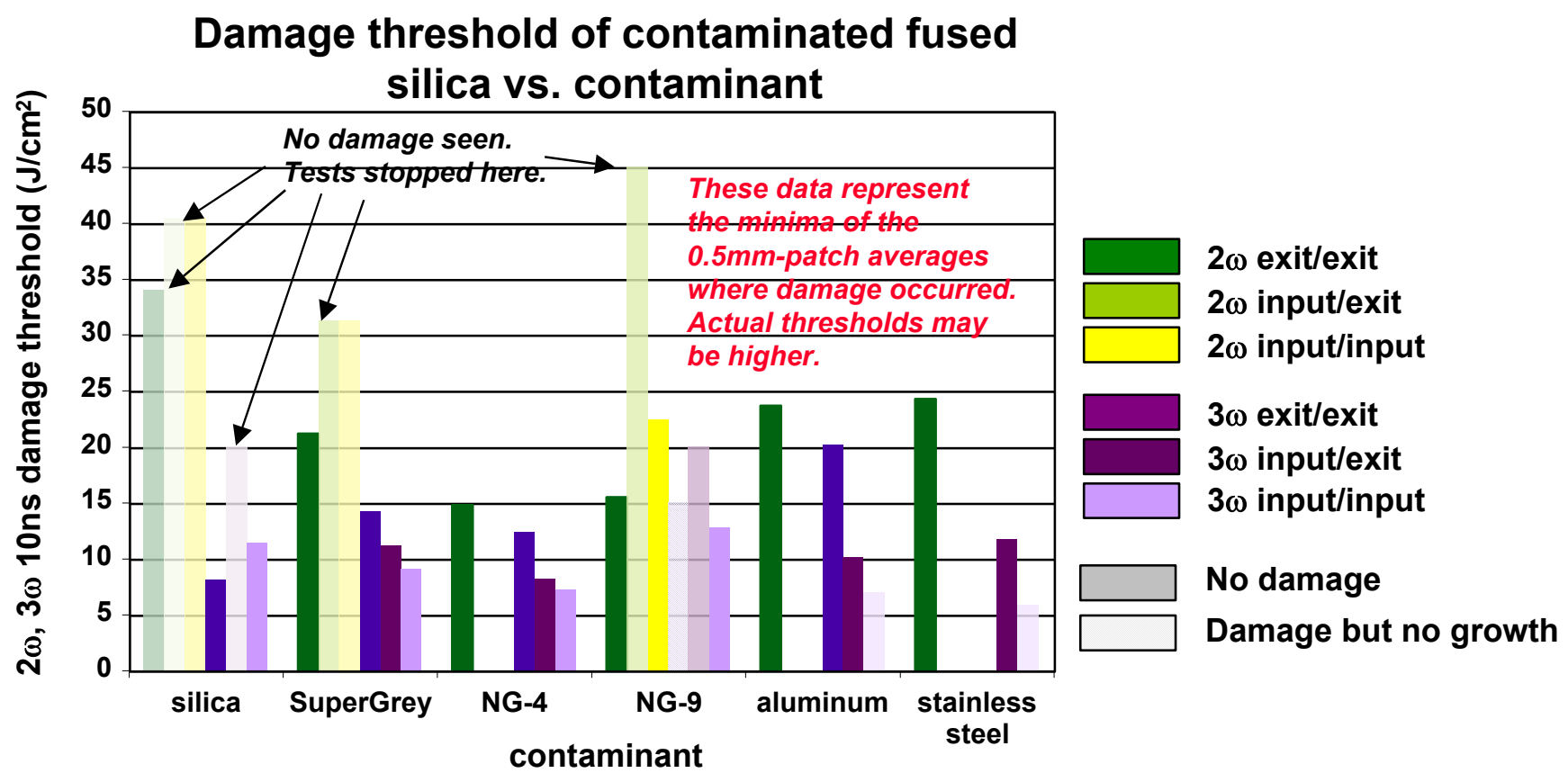

Figure 12. Summary of the damage thresholds of fused silica surfaces in the presence of contaminants. 


\section{MODELING}

In order to incorporate these results into a laser model, it is necessary to determine the functional form of both the probability of damage as a function of fluence as well as the damage threshold as a function of contaminant size. During the data reduction of this experiment, it was observed that for a given contaminant species of size $\geq 150 \mu \mathrm{m}$, the probability of damage as a function of threshold damage fluence went from zero to one over a range of $\sim 3-4 \mathrm{~J} / \mathrm{cm}^{2}$, centered at the nominal damage threshold fluence. If the damage threshold of fused silica for a given contaminant species and size at a given fluence is gaussian, we can represent the probability of damage in mathematical form with an error function, or

$$
f(\phi)=0.5\left[1+\operatorname{erf}\left(\chi\left(\phi-\phi_{o}\right)\right)\right]
$$

where $\phi_{o}$ is the nominal damage threshold,

$\phi$ is the input fluence,

$\gamma$ is a pseudo measure of the error function slope,

$f(\phi)$ is the damage probability, and

$\gamma=0.6 \mathrm{~cm}^{2} / \mathrm{J}$ is a good fit to the experimental data.

Earlier work by Génin ${ }^{4}$ showed that the damage threshold fluence of contaminated fused silica depends upon the contaminant species and is a decreasing function of contaminant size. The results from one of those experiments are shown in Fig. 13. These data can be fit to an exponential, where the y-intercept can be thought of as the intrinsic damage threshold fluence of the clean, fused silica surface and the asymptotic value is the damage threshold of a fully contaminated fused silica surface. In mathematical form, the damage threshold fluence as a function of contaminant size can be modeled by

$$
\phi_{o}(d)=\phi_{o, d i r t}+\left(\phi_{o, o p t i c}-\phi_{o, d i r t}\right) e^{-d / d_{o}}
$$

where $d$ is the contaminant size,

$d_{o}$ is a characteristic contaminant size

$\phi_{o, o p t i c}$ is the intrinsic damage threshold fluence of a clean fused silica surface,

$\phi_{o, \text { dirt }}$ is the intrinsic damage threshold fluence of a fully contaminated fused silica surface,

$\phi_{o}(d)$ is the nominal damage threshold for a contaminant of size $d$, and

$d_{o}=40 \mu \mathrm{m}$ is a good fit to the experimental data.

Inserting equation (2) into equation (1) gives the probability of damage as a function of fluence and contaminant size. The resultant distribution is a surface $(\phi, d)$ space as shown in Fig. 14. A summary and tabulation of the fitting parameters for the data obtained in this experiment is shown in the table below. 


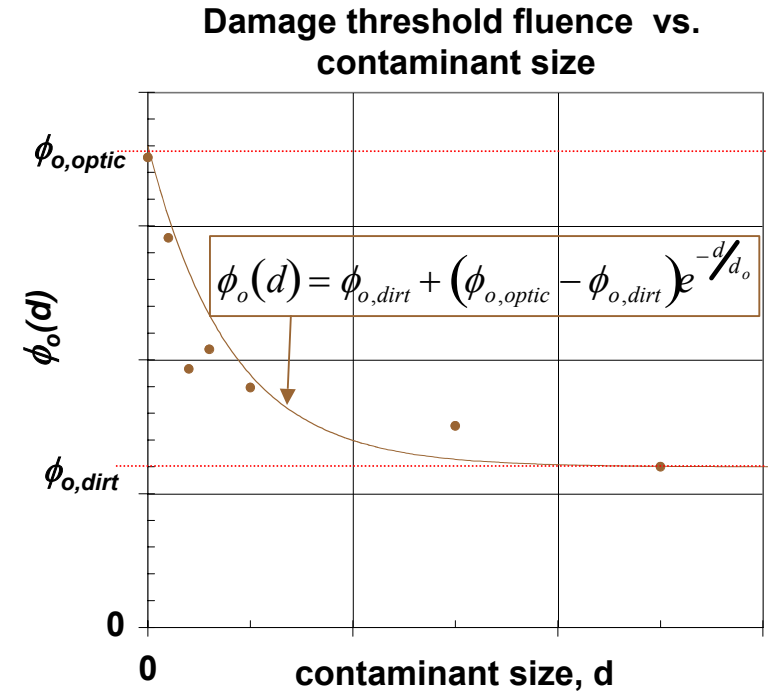

Figure 13. Data from Génin ${ }^{4}$ showing the damage threshold fluence as a function of contaminant size.
Probability of damage, $f(\phi, d)$, as a function of fluence and contaminant size

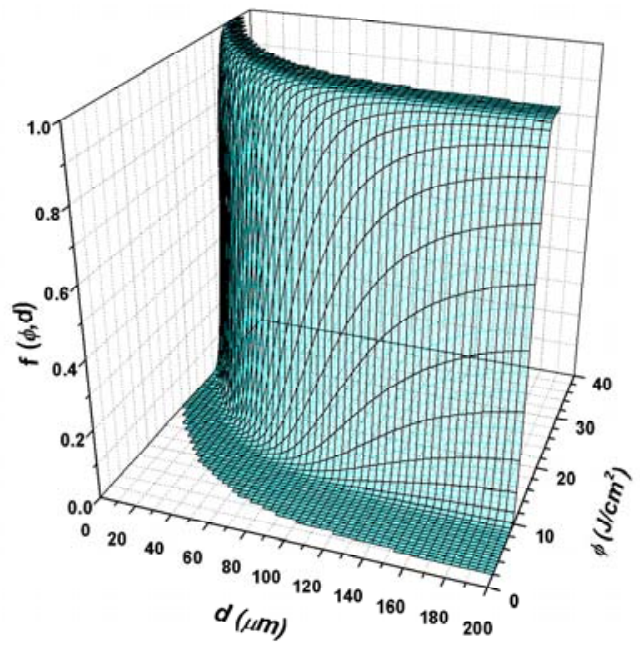

Figure 14. A typical shape for the probability of fused silica surface damage due to a given contaminant of size $d$ at a laser fluence $\phi$.

\begin{tabular}{|c|c|c|c|c|c|c|}
\hline Parameter & $\begin{array}{c}2 \omega \text { exit } \\
\text { SuperGrey }\end{array}$ & $\begin{array}{c}2 \omega \text { exit } \\
\text { aluminum }\end{array}$ & $\begin{array}{c}3 \omega \text { exit } \\
7940\end{array}$ & $\begin{array}{c}3 \omega \text { exit } \\
\text { SuperGrey }\end{array}$ & $\begin{array}{c}3 \omega \text { input/input } \\
7940 \\
\end{array}$ & $\begin{array}{c}3 \omega \text { input/input } \\
\text { SuperGrey }\end{array}$ \\
\hline$\phi_{\text {optic }}\left(\mathrm{J} / \mathrm{cm}^{2}\right)$ & 70 & 20 & 30 & 30 & 35 & 35 \\
\hline$\phi_{\text {dirt }}\left(\mathbf{J} / \mathbf{c m}^{2}\right)$ & 20 & 23 & 9 & 12 & 9 & 9 \\
\hline$d_{o}(\mu \mathrm{m})$ & 40 & 40 & 40 & 40 & 40 & 40 \\
\hline$\gamma\left(\mathrm{cm}^{2} / \mathbf{J}\right)$ & 0.6 & 0.6 & 0.6 & 0.6 & 0.6 & 0.6 \\
\hline
\end{tabular}

Table 1. Summary of the fitting parameters that establish the probability of damage for a fused silica surface as given by Eqs. 1 and 2.

\section{SUMMARY}

Controlled experiments investigating the damage threshold of fused silica surfaces in the presence of typical contaminants (absorbing glass, fused silica, aluminum, and stainless steel) were performed. Data were obtained using $527-\mathrm{nm}$ and 351-nm, high-fluence, high-irradiation laser pulses. Contaminant particles were generated and deposited in the most realistic manner possible. Fused silica particles generated by a growing, pre-initiated damage site did not cause further damage when illuminated with $527-\mathrm{nm}$ light at fluences up to $41 \mathrm{~J} / \mathrm{cm}^{2}$. Absorbing glass contaminants had lower damage thresholds of the input surface than the exit surface.

Experimental data obtained here and previously were incorporated into a mathematical model. This model can be used to predict damage to fused silica surfaces in the presence of certain contaminants of known size and species. The model is general enough to be useful for other contaminants not studied here. 


\section{ACKNOWLEDGEMENTS}

The authors would like to thank Monica Antone and Trixie Evans for their support in preparing this manuscript. This work was performed under the auspices of the US Department of Energy by UC Lawrence Livermore National Laboratory under contract No. W-7405-Eng-48.

\section{REFERENCES}

${ }^{1}$ C.J. Stolz, R.J. Tench, M.R. Kozlowski, and A. Fornier, "A comparison of nodular defect seed geometries from different deposition techniques," Laser-Induced Damage in Optical Materials, Proc. SPIE 2714, 374-382 (1996).

${ }^{2}$ F.Y. Génin, M.D. Feit, M.R. Kozlowski, A.M. Rubenchik, A. Salleo, and J. Yoshiyama, "Rear-surface laser damage on 355-nm silica optics owing to Fresnel diffraction on front-surface contamination particles," Appl. Opt. 39, 3654-3663 (2000).

${ }^{3}$ F.Y. Génin, K. Michlitsch, J. Furr, M.R. Kozlowski, and P. Krulevitch, "Laser-induced damage of fused silica at 355 and $1064 \mathrm{~nm}$ initiated at aluminum contamination particles on the surface," Laser-Induced Damage in Optical Materials, Proc. SPIE 2966, 126-138 (1997).

${ }^{4}$ F.Y. Génin, M.R. Kozlowski, and R. Brusasco, "Catastrophic failure of contaminated fused silica optics at 355 nm," Solid State Lasers for Application to Inertial Confinement Fusion, Proc. SPIE 3047, 978-986 (1997).

${ }^{5}$ SuperGrey is a registered trademark for an architectural float glass manufactured by Pilkington Building Products, http://www.pilkington.com.

${ }^{6}$ NG4 and NG9 are neutral-density filter glasses manufactured by Schott, http://www.schott.com.

${ }^{7}$ C.B. Dane, L.E. Zapata, W.A. Neuman, M.A. Norton, and L.A. Hackel, "Design and operation of a 150W near diffractionlimited laser amplifier with SBS wavefront correction,” IEEE J. Quant. Electron. 31, 148-163 (1995).

${ }^{8}$ M.A. Norton, L.W. Hrubesh, Z. Wu, E.E. Donohue, M.D. Feit, M.R. Kozlowski, D. Milam, K.P. Neeb, W.A. Molander, A.M. Rubenchik, W.D. Sell, and P.J. Wegner, "Growth of laser initiated damage in fused silica at $351 \mathrm{~nm}$," Laser-Induced Damage in Optical Materials, Proc. SPIE 4347, 468 (2001).

${ }^{9}$ M.A. Norton, E.E. Donohue, W.G. Hollingsworth, J.N. McElroy, and R.P. Hackel, "Growth of laser initiated damage in fused silica at 527 nm," Laser-Induced Damage in Optical Materials, Proc. SPIE 5273, 236-243 (2004). 